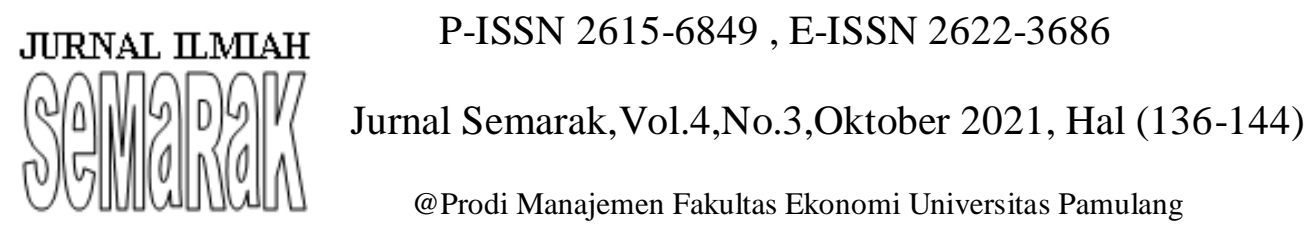

Jurnal Semarak, Vol.4,No.3,Oktober 2021, Hal (136-144)

@Prodi Manajemen Fakultas Ekonomi Universitas Pamulang

\title{
PENGARUH KUALITAS PELAYANAN TERHADAP KEPUASAN MAHASISWA FAKULTAS EKONOMI DAN BISNIS PRODI SARJANA MANAJEMEN UNIVERSITAS PAMULANG
}

\author{
Fadillah \\ Assiten Ahli Fakultas Ekonomi dan Bisnis Universitas Pamulang \\ dosen unpam, email : dosen02197@unpam.ac.id
}

\begin{abstract}
ABSTRAK
Tujuan kajian ini adalah seperti berikut: Untuk mengetahui kesan kualiti perkhidmatan terhadap kepuasan pelajar di Universiti Pamulang. Kaedah yang digunakan dalam kajian ini menggunakan analisis deskriptif kuantitatif, sedangkan menurut Sugiyono (2012: 147), adalah "kaedah yang digunakan untuk menggambarkan atau menganalisis hasil penyelidikan tidak digunakan untuk membuat kesimpulan yang lebih luas". Teknik yang digunakan adalah kebarangkalian pengambilan sampel dengan menggunakan kawasan persampelan (cluster sampling). Sebab penggunaan teknik persampelan ini sekiranya didapati bahawa objek atau responden yang dikaji sangat luas. Setelah memilih sampel terkecil, maka sampel rawak dipilih. Kualiti perkhidmatan memberi kesan positif dan signifikan terhadap kepuasan pelajar. Hasil kajian ini menunjukkan bahawa aritmetik $t$ adalah 1.976 lebih besar daripada t jadual 2.00 dengan nilai sig $0.000<0.05$, maka Hol ditolak dan Ha1 diterima. Yang bermaksud bahawa kualiti perkhidmatan memberi kesan positif dan signifikan terhadap pemboleh ubah kepuasan pelajar.
\end{abstract}

\section{Kata Kunci : Kualitas Pelayanan, Kepuasan}

\begin{abstract}
The purpose of this study is as follows: To determine the effect of service quality on student satisfaction at Pamulang University. Quantitative descriptive method according to Sugiyono (2012:147), is "the method used to describe or analyze a research result is not used to make broader conclusions". Quantitative methods carried out through a correlational approach are used for the process of testing the research hypothesis, namely the extent to which variations in one root are related to other root variations. The technique used is probability sampling by using area sampling (cluster sampling). This sampling technique is used when the object under study is very broad. After selecting the smallest sample, then a random sample is selected. Service quality has a positive and significant effect on student satisfaction. The results of this study indicate that $t$ arithmetic 19.762 is greater than t table 2.00 with a sig value of $0.000<$ 0.05 , then Hol is rejected and Hal is accepted. Which means that the quality of service has a positive and significant effect on the student satisfaction variable.
\end{abstract}

Keywords: service quality, satisfaction

I. PENDAHULUAN

A. Latar Belakang

Perkembangan "dunia" pendidikan menuntut kualiti sumber manusia yang kompeten. Institusi pendidikan berusaha

"memberikan perkhidmatan yang berkualiti dan infrastruktur yang mencukupi" agar sesuai dengan apa yang 
diharapkan oleh para pelajar. Keupayaan Pengajian Tinggi "untuk pencapaian kualiti graduan yang cekap dan kreatif dalam bidangnya juga menjadi kebanggaan" untuk kejayaan universiti itu sendiri. "Program aktiviti yang dibuatnya dapatdibuktikan denngan kualiiti hasil pendidikan dilihat oleh semua pelajar. Bukkti pencapaian, penilaian, pensijilan kompetensi, kejayaan alumni dalam memperoleh pekerjaan yang menjadi penanda aras kejayaan pendidikan tinggi yang akan dikenali oleh semua lapisan masyarakat. Untuk mengekalkan persaingan di tengah-tengah perniagaan pendidikan yang semakin pelbagai, universiti harus memberi perhatian kepada kualiti perkhidmatan yang diberikan kepada pelajar.pelajar supaya pelajar ini merasa puas dan merasa dijaga oleh institusi pendidikan, agar pelajar tidak kecewa sehingga skala untuk melamar pelajar baru sangat terbuka. Pelajar akan merasa gembira sekiranya kritikan dan cadangan mereka diterima oleh pihak universiti dan pihak universiti segera memperbaikinya. Dengan tindak balas universiti yang sangat pantas dalam meningkatkan kualiti perkhidmatan kepada pelajar, pelajar mesti sangat menghormati universiti. Kepuasan pelajar adalah kunci kejayaan universiti agar universiti dapat bersaing dengan pesaingnya.

Di samping itu, kepuasan pelajar juga merupakan parameter yang sangat penting bagi universiti agar perniagaan dapat terus berkekalan. Walau bagaimanapun, kepuasan pelajar juga bergantung pada keputusan universiti untuk mengambil tindakan pembetulan dalam perkhidmatan yang akan memberi kesan kepada membina dan mengikat kesetiaan pelajar.

Menurut Kotler dalam buku Sunyoto (2013:35), kepuasan pengguna adalah tahapan perasaan seseorang setelah membandingkan pencapaian atau hasil yang dirasakan dengan harapannya. Pengguna dapat mengalami salah satu dari tiga tahap kepuasan umum, yaitu jika kinerja di bawah harapan, pengguna akan merasa kecewa, tetapi jika kinerja sesuai dengan harapan, pelanggan akan merasa puas dan jika kinerja melebihi harapan, pelanggan akan merasa puas. pelanggan akan merasa sangat puas, senang atau puas. bergairah. Sedangkan menurut teori Kotler dalam jurnal Suwardi (2011), kunci untuk mempertahankan pelanggan adalah kepuasan pelanggan. Petunjuk kepuasan pengguna dapat dilihat dari:

1. Re-purchase: beli semula, pelanggan yang menjadi pelanggan akan kembali ke syarikat untuk mencari barang / perkhidmatan.

2. Menciptakan Word-of-Mouth: Dalam kes ini, pelanggan akan mengatakan perkara baik mengenai syarikat itu kepada orang lain.

3. Menciptakan Citra Merek: Pelanggan akan memperhatikan jenama dan iklan produk pesaing.

4. Menciptakan Keputusan pembelian di syarikat yang sama: Beli produk lain dari syarikat yang sama.

Dari pernyataan "di atas dapat diambil kesimpulan pada kualiti perkhidmatan" yang mempengaruhi kepuasan mahasiswa, mulai dari realibilitas, ketanggapan, jaminan, empati hingga kepuasan mahasiswa sehingga memberikan dampak terhadap universitas.

Tabel 1 Mahasiswa Unpam

Data Statistik Mahasiswa Prodi Sarjana Manajemen Tahun 2020 \begin{tabular}{|c|c|c|}
\hline $\begin{array}{c}\text { Mahasiswa Prodi } \\
\text { Lainnya }\end{array}$ & $\begin{array}{c}\text { Mahasiswa } \\
\text { Prodi } \\
\text { Sarjana } \\
\text { Manajemen }\end{array}$ & Total Mahasiswa Aktif \\
\hline 48.000 & 22.000 & 70.000 \\
\hline Sumber: Staf Prodi Manajemen tahun 2020 &
\end{tabular}

Berdasarkan pada tabel di atas, jumlah mahasiswa aktif berjumlah sekitar 22.000 di prodi sarjana manajemen pada tahun 2020.

Tabel 2 Keluhan Mahasiswa Prodi Sarjana Manajemen

Data Keluhan Mahasiswa Prodi Manajemen Tahun 2020 \begin{tabular}{|l|l|l}
\hline No. & Jenis Keluhan & Alasan keberatan Mahasiswa \\
\hline 1. & Pembayaran melalui loket dan antri & $\begin{array}{l}\text { Karena tidak melakukan } \\
\text { pembayaran melalui ATM }\end{array}$ \\
\hline 2. & $\begin{array}{l}\text { Pelayanan yang kurang ramah di } \\
\text { ruang loket pembayaran }\end{array}$ & $\begin{array}{l}\text { Harusnya Staf loket pembayaran } \\
\text { ramah terhadap mahasiswa }\end{array}$ \\
\hline 3. & Kebersihan toilet kurang memadai & Alasan protokol kesehatan \\
\hline 4. & $\begin{array}{l}\text { Kebersihan kantin dan fasilitas } \\
\text { kurang diperhatikan }\end{array}$ & $\begin{array}{l}\text { Kenyamanan dan fasilitas bangku di } \\
\text { kantin tidak memadai }\end{array}$ \\
\hline 5. & $\begin{array}{l}\text { Ruang kelas ada beberapa tidak } \\
\text { menggunakan AC }\end{array}$ & $\begin{array}{l}\text { Mahasiswa merasa kurang nyaman } \\
\text { dengan suhu udara yang panas }\end{array}$ \\
\hline \multicolumn{2}{|l}{ Sumber: Mahasiswa Prodi Manajemen tahun 2020 }
\end{tabular} 
Berdasarkan Tabel 2 tampak bahwa Data keluhan mahasiswa prodi sarjana manajemen secara spesifik memang penulis tidak memiliki jumlah statistik secara rinci karena terkait privasi data, namun sejumlah keluhan di atas cukup menjadi keberatan mahasiswa akhir-akhir ini yang jika tidak dikendalikan dengan baik maka akan menjadi boomerang bagi pihak prodi sarjana manajemen, baik jangka pendek dan jangka panjang. Jika dalam perkhidmatan menyediakan hubungan memuaskan atau hubungan kebutuhan bagi mahasiswa.

Berdasarkan hasil penelitian di Prodi Sarjana Manajemen terlihat bahwa kebersihan diruang toilet dan kantin serta di setiap ruangan kelas masih ada yang tidak memakai AC, ruang parkir yang terbatas.

Atas dasar penjelasan yang dijabarkan sebelumnya, penulis berminat untuk mengambil pneelitian yang bertajuk "Pengaruh Kualitas Pelayanan Terhadap Kepuasan Mahasiswa Ekonomi dan Bisnis Prodi Sarjana Manajemen Universitas Pamulang”.

\section{B. Rumusan Masalah.}

Merangkum dari pembahasan sebelumnya, penulis mencatat perumusan masalah dibawah ini:

1. Bagaimana kualiti kualiti perkhidmatan terhadap kepuasan pelajar di Universitas Pamulang?

\section{Tujuan Penelitian}

Setelah membuat rumusan dan analisis masalah yang telah dijelaskan sebelumnya, kajian ini bertujuan untuk:

1. Untuk mengetahui kesan kualiti perkhidmatan terhadap kepuasan pelajar di Universiti Pamulang.

\section{TINJAUAN PUSTAKA}

\section{A. Kualitas Layanan}

\section{Pengertian Kualitas Pelayanan}

Menurut Wyckof dalam Lovelock yang dikutip oleh Tjiptono "(2014:268)," kualitas pelayanan adalah tingkat keunggulan yang diharapkan oleh pelanggan dan pengendalian atas keunggulan tersebut untuk memenuhi keinginan pelanggan atau konsumen. Menurut Tjiptono dalam bukunya (2012:41), kualitas pelayanan adalah keadaan dinamis yang berkaitan erat dengan produk atau barang, jasa, manusia atau manusia, proses atau pengolahan dan lingkungan (environment) yang memenuhi atau melebihi harapan pelanggan. atau konsumen. sehingga pengertian kualitas pelayanan dapat diartikan sebagai upaya pemenuhan kebutuhan dan keinginan konsumen serta ketepatan penyampaian dalam menyeimbangkan harapan konsumen. Kualiti perkhidmatan adalah perkhidmatan yang diharapkan (perkhidmatan yang diharapkan) dan perkhidmatan yang dirasakan (perkhidmatan yang diterima).

Sekiranya perkhidmatan yang diterima sesuai dengan apa yang diharapkan, maka perkhidmatan tersebut dikatakan baik atau positif. Sekiranya perkhidmatan yang dirasakan melebihi perkhidmatan yang diharapkan, maka kualiti perkhidmatan dianggap sebagai kualiti yang ideal. Sebaliknya, jika perkhidmatan yang dirasakan lebih buruk daripada perkhidmatan yang diharapkan, maka kualiti perkhidmatan dianggap negatif atau buruk. Oleh itu, sama ada kualiti perkhidmatan baik atau tidak bergantung pada kemampuan syarikat dan kakitangannya untuk memenuhi harapan pelanggan secara konsisten.

\section{Indikator Kualitass Pelayanann}

Menurut Tjiptono (2017:159) ada ada lima dimensi kualiti perkhidmatan yang dijabarkan sesuai tingkatnya sebagai berikut :

a. Reliabilitas (Reliability), berkaitan dengan kemampuan syarikat untuk memberikan perkhidmatan yang tepat pada kali pertama.

b. Reliability (Reliability), berkaitan dengan kemampuan syarikat untuk memberikan perkhidmatan yang 
dijanjikan dengan tepat sejak pertama kali.

c. Tanggungjawab, mengenai kesediaan dan kemampuan penyedia perkhidmatan untuk membantu pelanggan dan segera memenuhi permintaan mereka.

d. Jaminan, berkaitan dengan pengetahuan dan kesopanan pekerja di mana kemampuan individu untuk menumbuhkan kepercayaan atau keyakinan diri.

e. Empati, yang bermaksud bahawa syarikat memahami masalah pelanggannya dan bertindak demi kepentingan pelanggan, dan memberikan perhatian peribadi kepada pelanggan dan mempunyai waktu operasi yang selesa.

f. Bukti fizikal (tangibles), yang berkaitan dengan penampilan fizikal kemudahan perkhidmatan, peralatan, sumber manusia, dan bahan komunikasi syarikat.

\section{B. Kepuasan Pelanggan}

\section{Pengertian Kepuasan Pelanggan}

Menurut Tjiptono (2014:353) kepuasan pelanggan adalah perasaan senang atau kecewa seseorang yang timbul setelah membandingkan persepsi atau tanggapannya terhadap prestasi yang berada di bawah jangkaan, pelanggan tidak berpuas hati. Namun, sekiranya prestasi melebihi jangkaan, pelanggan sangat berpuas hati dan gembira. Sekiranya prestasi yang dirasakan berada di bawah jangkaan, pelanggan akan merasa kecewa, jika prestasi memenuhi harapan pelanggan, pelanggan akan merasa puas, sedangkan jika prestasi melebihi jangkaan, pelanggan akan merasa sangat puas.

Selain itu, kepuasan Selain itu, kepuasan pelanggan juga dipandang sebagai salah satu indikator terbaik untuk pendapatan masa depan (Fornell, dalam Kotler \& Keller, 2012). Fakta bahwa menarik pelanggan baru jauh lebih mahal daripada mempertahankan pelanggan lama juga menjadi salah satu pemicu meningkatnya perhatian terhadap kepuasan pelanggan menurut Fornell \& Wenerfelt, dikutip dalam buku pemasaran jasa (Fandy Tjiptono, 2014: 353) .

\section{Indikator Kepuasan Pelanggan}

Menurut Tjiptono (2014:368) dimensi kepuasan pelanggan adalah:

a. Kepuasan Pelanggan Keseluruhan.

Dalam konsep ini, cara untuk mengukur kepuasan pelanggan adalah dengan langsung bertanya kepada pelanggan betapa puasnya mereka dengan produk atau perkhidmatan syarikat. Penilaian termasuk mengukur tahap kepuasan pelanggan dengan produk dan / atau perkhidmatan syarikat dan membandingkannya dengan tahap kepuasan pelanggan dengan syarikat yang bersaing.

b. Dimensi Kepuasan Pelanggan.

Kepuasan pelanggan diukur dengan empat langkah. Pertama, kenal pasti dimensi utama kepuasan pelanggan. Kedua, meminta pelanggan menilai produk dan / atau perkhidmatan syarikat. Ketiga, meminta pelanggan menilai produk dan / atau perkhidmatan syarikat pesaing berdasarkan item yang sama. Dan keempat, meminta pelanggan menentukan dimensi yang penting dalam menilai kepuasan pelanggan.

c. Konfirmasi Harapan (Confirmation Of Expectations).

Kepuasan diukur berdasarkan kesesuaian / ketidakcocokan antara harapan pelanggan dengan prestasi produk / perkhidmatan syarikat.

d. Niat Beli Ulang (Repurchase Intention ).

Dalam konsep ini, caranya adalah dengan bertanya kepada pelanggan secara langsung sama ada membeli produk atau menggunakan perkhidmatan syarikat lagi. 
e. Kesediaan untuk merekomendasi (Willingness to Recommend).

Kesediaan pelanggan untuk mengesyorkan produk / perkhidmatan kepada rakan atau keluarga menjadi ukuran penting untuk dianalisis dan ditindaklanjuti dalam hal pembelian produk / perkhidmatan yang pembelian berulang agak lama.

f. Ketidakpusan Pelanggan (Customer Dissatisfaction).

Ktidakpuasn pelangan merangkumi aduan, pengembalian produk, kos jaminan, penarikan balik produk (pengeluaran produk dari pasaran), mulut ke mulut negatif, dan pembelotan (pengguna yang beralih kepada pesaing).

\section{Hubungan Kualitas Pelayanan Terhadap Kepuasan \\ Perkhidmatan berkualiti memainkan} peranan penting dalam membentuk kepuasan pelanggan, kualiti memberi dorongan kepada pelanggan untuk menjalin ikatan atau hubungan yang kuat dengan syarikat. Dalam jangka masa panjang, bil ini membolehkan syarikat memahami kehendak pelanggan dengan teliti. Kepuasan kualiti dan perkhidmatan, menurut Tjiptono dalam Setyaji (2015:3) memiliki hubungan yang erat dengan kepuasan pelanggan. Kualiti memberi dorongan kepada pelanggan untuk menjalin hubungan yang kuat dengan syarikat.

\section{Hipotesis Penelitian}

Berikut di bawah ini dugaan sementara yang dapat dihasilkan dari penelitian berdasarkan paparan sebelumnya di latarbelakang, mindmap maupun kajian teori:

$\mathrm{H}_{\mathrm{o}}$ : Tidak ada kesan kualiti perkhidmatan terhadap kepuasan pelajar prodi sarjana manajemen Universitas Pamulang
$\mathrm{H}_{\mathrm{a}}$ : Terdapat pengaruh kualiti perkhidmatan terhadap kepuasan

pelajar prodi sarjana manajemen Universitas Pamulang.

\section{METODE PENELITIAN}

Penyelidikan ini dilakukan untuk mengetahui bagaimana pengaruh kualiti perkhidmatan terhadap kepuasan pelajar dalam program pengajian sarjana pengurusan. Dalam hal ini, objek kajian adalah Universiti Pamulang yang terletak di Jl. Surya Kencana No.1, Pamulang, Tangerang Selatan, Banten.

Dengan menggunakan Metode penelitian kuantitatif, peneliti menguji sampel dari populasi, menganalisa data statistik untuk menguji dugaan sementara.

Dalam kajian ini, semua subjek atau objek diperiksa sehingga dapat disebut sampel. Populasi dalam kajian ini adalah pelajar Program Pengajian Pengurusan S1 di Universiti Pamulang untuk tempoh 2019 hingga 2020. Kajian ini menggunakan teknik Incidental Sampling, yang merupakan teknik persampelan berdasarkan peluang, iaitu sesiapa sahaja yang secara kebetulan / kebetulan bertemu dengan penyelidik. boleh digunakan sebagai sampel jika dianggap bahawa orang yang kebetulan ditemui sesuai sebagai sumber data (Sugiyono, 2013:124), sehingga sampel yang digunakan dalam kajian ini adalah pelajar yang kebetulan datang dan bertemu dengan penyelidik di program pengajian pengurusan. Universiti Pamulang. Jumlah sampel dalam kajian ini ditentukan, berdasarkan formula Slovin yang dikutip oleh Umar (2005), sebagai berikut: $n=\mathrm{N} 1+\mathrm{Ne} 2$

Keterangan :

$\mathrm{n}=$ ukuran sampel

$\mathrm{N}=$ jumlah populasi

$\mathrm{e}=$ sampling eror $(10 \%)$

Kajian ini menggunakan skor dalam bentuk skala Likert.

\section{Tabel 4}


Skala Likert

\begin{tabular}{|c|c|}
\hline Alternatif Jawaban & SKOR \\
\hline Sangat Setuju & 5 \\
\hline Setuju & 4 \\
\hline Ragu-ragu & 3 \\
\hline Tidak Setuju & 2 \\
\hline Sangat Tidak Setuju & 1 \\
\hline
\end{tabular}

\section{HASIL DAN PEMBAHASAN}

\section{A. Gambaran Objek Penelitian \\ 1. Uantuar an Uojun \& Unyununan}

Universiti Pamulang atau diperbadankan dalam Yayasan Kumpulan Sasmita Jaya ditubuhkan pada tahun 2000 oleh Yayasan Prima Jaya yang dipengerusikan oleh Drs. Wayan. Walau bagaimanapun, kerana mereka tidak dapat menangani Yayasan Prima Jaya dalam menguruskan Universiti, mereka memindahkannya ke Yayasan Kumpulan Sasmita Jaya pada awal tahun 2005. Setelah menukar pengurusan, matlamat yang ingin dicapai oleh Universiti Pamulang juga berubah.

\section{B. Penemuan dan Pembahasan}

\section{Validity Test}

Uji validitas dilakukan untuk melihat seberapa besar akurasi alathitung berupa kuisioner sebagai instrumentasi penelitian dapat menghitung secara valid sesuai dengan keadaan sebenarnya. Berdsasrkan pada nilai r-tabel dengan kondisi jumlah populasi sekaligus sample penelitian sebanyak 100 orang maka nilai $\mathrm{df}=$ 100 , dengan siginfikansi $5 \%$, mala nulai r-tabel sama dengan 0,196. Perbandingan r-hituing dengan $\mathrm{r}$-tabel jika lebih besar dari r-tabel, maka nilainya valid, sementara jika r-hitung lebih kecil drpd r-tabel maka tidak valid, dan pernyataan tersebut harus diubah atau diganti dengan pernyataan lain.

Fungsi darinya adalah untuk menguji setiap penyataan soal selidik atau instrumen yang diukur untuk menentukan kesahan suatu data .

Formula Product Moment:

$$
r_{x y}=\frac{N \sum x y_{-\left(\sum x\right)}\left(\sum y\right)}{\sqrt{\left(N \Sigma x^{2}-\left(\sum x\right)^{2}\left(N \Sigma y^{2}-\left(\sum y\right)^{2)}\right.\right.}}
$$

Note:

$$
\begin{aligned}
& r_{x y}=\text { Koefisien korelasi antara variabel } \mathrm{X} \text { dan variabel } \mathrm{Y} \\
& \sum x \mathrm{y}=\text { Jumlah perkalian antara variabel } \mathrm{x} \text { dan } \mathrm{Y} \\
& \sum x^{2}=\text { Jumlah dari kuadrat nilai } \mathrm{X} \\
& \sum y^{2}=\text { Jumlah dari kuadrat nilai } \mathrm{Y} \\
& \left(\sum x\right)^{2}=\text { Jumlah nilai } \mathrm{X} \text { kemudian dikuadratkan }
\end{aligned}
$$

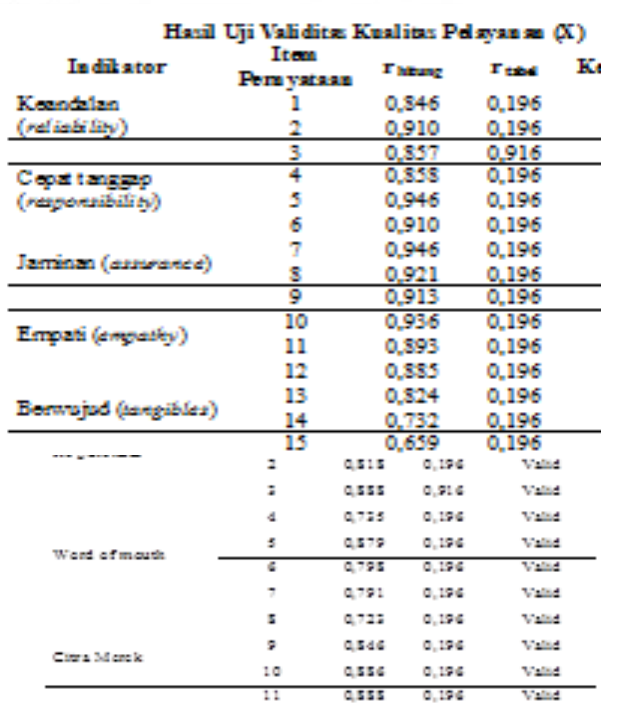

Hasil pengịịaan seperti: jadual :keputusan: kesahan

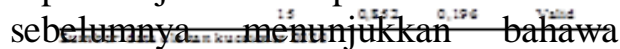
keseluruhan rcount lebih besar daripada nilai rable (0.1832). Oleh itu, dapat disimpulkan bahawa pernyataan dalam tinjauan ini adalah sah dan dapat digunakan sebagai instrumen kajian.

\section{Pengujian Reliabilitas}

Berikut hasil uji reliabilitas dijelaskan di bawah ini .

Tabel 6 Hasil Reliabilitas

\begin{tabular}{ccc} 
& \multicolumn{3}{c}{ Hasil Uji Reliabilitas } & \\
\hline Variabel & Cronbach Alpha & Keterangan \\
Kualitas Pelayanan (X) & 0,976 & Reliabel \\
Kepuasan Mahasiswa (Y) & 0,966 & Reliabel \\
\hline
\end{tabular}


Dari hasil uji Kebolehpercayaan, nilai Cronbach alpha untuk semua pemboleh ubah adalah $>$ dari0,600. Ini sesuai dengan Sugiyono (2013) dalam perbincangannya, di mana semua nilai Cronbach Alpha yang dikira adalah > 0,60 dan ini bermaksud bahawa semua data boleh dipercayai.

Tabel 9 Hasil Uji Partial t

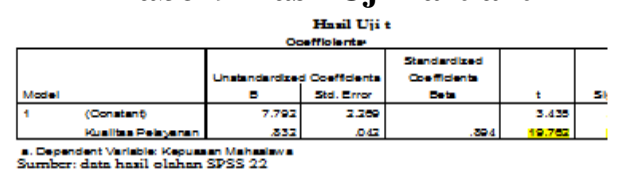

\section{Hasil Pengujian Pengaruh Kualitas Pelayanan Terhadap Kepuasan Mahasiswa}

Berdasarkan Jadual 9, dapat dilihat bahawa nilai t-count pada pemboleh ubah Quality Service (X1) lebih besar daripada nilai t-table $(3.414>1.976)$ dengan nilai signifikansi pemboleh ubah Quality Service (X) $0.001<0.05$ sehingga Ho ditolak dan Ha diterima, yang bermaksud bahawa terdapat pengaruh positif dan signifikan terhadap Kualiti Perkhidmatan terhadap Kepuasan Pelajar.

\section{Pengaruh Secara Bersamaan (Simultanous)}

Uji pengaruh secara bersama atau simultan, dengan kata lain Uji $F$ mnejelaskan ada atau tidaknya signifikansi hasil analisis regresi. Disini digunakan signifikansi $5 \%$ atau 0,05 ; dimana jika nilai sig. lebih besar daripada 0,05 maka $\mathrm{H}$ nol ditolak dan $\mathrm{H}$-a diterima

Tabel 10 Hasil Uji Simultan F

\begin{tabular}{|l|r|r|r|c|c|}
\hline Model & Sum of Squares & df & Mean Square & F & Sig. \\
\hline Regression & 392.622 & 2 & 196.311 & 20.290 & $.000^{\circ}$ \\
1 Residual & 503.124 & 52 & 9.675 & & \\
Total & 895.745 & 54 & & & \\
\hline
\end{tabular}
a. Dependent Variable: Kinerja
b. Predictors: (Constant), Pengalaman_Kerja, Lingkungan_Kerja

Berdasarkan Jadual 10, dapat dilihat bahawa nilai signifikansi adalah $0.000<0.05$ maka $\mathrm{H}_{\mathrm{o}}$ ditolak dan $\mathrm{H}_{\mathrm{a}}$ diterima, dapat dinyatakan bahawa persekitaran kerja dan pengalaman kerja bersama-sama mempengaruhi prestasi pekerja .

\section{Koefiisien Determinasi}

KoefisiensiDeterminasi dipakai untuk mnentukan besaar peengaruh antar variabel bebas ke variabel terikat.

TabeL 11 Koef Determinasi

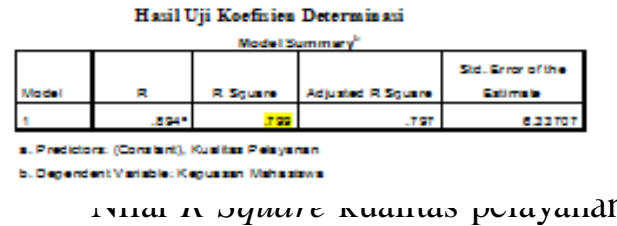

(X) adalah 0.799 atau $79 \%$ yang berarti besarnya pengaruh kualitas pelayanan terhadap kepuasan mahasiswa adalah sebesar 79

\section{KESIMPUL AN \& SARA N}

\section{A. Kesimpu lan}

Perkara-perkara berikut dapat disimpulkan oleh penyelidik berdasarkan analisis yang dilakukan sebelumnya:

1. Kualiti perkhidmatan memberi kesan positif dan signifikan terhadap kepuasan pelajar. Hasil kajian ini menunjukkan bahawa aritmetik $\mathrm{t}$ adalah 1.976 lebih besar daripada $\mathrm{t}$ jadual 2.00 dengan nilai sig 0.000 $<0.05$, maka Ho ditolak dan $\mathrm{Ha}$ diterima. Yang bermaksud bahawa kualiti perkhidmatan memberi kesan positif dan signifikan terhadap pemboleh ubah kepuasan pelajar.

B. Saran

Berdasarkan dapatan kajian, perbincangan dan kesimpulan. Penulis memberikan beberapa cadangan agar Universiti Pamulang dipertimbangkan dan menjadi input bagi syarikat seperti berikut :

1. Poin terendah pada indikator Berwujud pernyataan Lahan parkir terawat dengan baik dan dimanfaatkan oleh mahasiswa dengan maksimal dengan skor 3,11 . Oleh karena itu hendaknya lahan parkir untuk prodi sarjana manajemen lebih diperluas lagi dengan tambahan pelindung atap. 
2. Indikator Keputusan Pembelian dengan pernyataan Harapan Saya menjadi lebih mandiri dan berprestasi ketika memutuskan kuliah di UNPAM dengan skor 2,95. Hendaknya UNPAM memperbaiki kualitas pendidikan serta mencetak lulusan yang siap kompetensi dengan daya saing unggul untuk kedepannya.

\section{Bagi Peneliti Selanjutnya}

\subsection{Agenda Penelitian Mendatang}

Berdasarkan dapatan, kesimpulan dan cadangan, penulis mencadangkan untuk menambahkan pemboleh ubah bebas yang lain selain kualiti perkhidmatan sebagai pemboleh ubah bebas yang boleh mempengaruhi pemboleh ubah bersandar, iaitu kepuasan pelajar untuk menyelesaikan penyelidikan kerana masih terdapat banyak pemboleh ubah bebas lain di luar penyelidikan yang boleh mempengaruhi kepuasan pelajar.

\section{DAFTAR PUSTAKA}

Ghozali, Imam. 2016. Aplikasi Analisis Multivariate Dengan Program SPSS. Penerbit Badan Penerbit Universitas Diponegoro.

Haryoko, U. B., Pasaribu, V. L. D., \& Ardiyansyah, A. (2020). PENGARUH HARGA DAN KUALITAS PELAYANAN TERHADAP KEPUASAN KONSUMEN PADA FIRMAN DEKORASI (WEDDING ORGANIZER). POINT: Jurnal Ekonomi Dan Manajemen, 2(1).

Kotler, P., \& Keller, K. 2016. Edisi 13. Manajemen Pemasaran. Jakarta: Erlangga

Limakrisna, Nandan dan Togi Parulian Purba. 2019. Manajemen Pemasaran. Jakarta: Mitra Wacana Media

Pasaribu, V. L. D. (2020). ANALISIS PENGARUH PROMOSI, KUALITAS PRODUK DAN DESAIN KEMASAN TERHADAP KEPUTUSAN PEMBELIAN HAND AND BODY LOTION MEREK CITRA (Studi Kasus Carrefour Pamulang,
Tangerang Selatan). Jurnal Pemasaran Kompetitif, 1(4).

Pasaribu, V. L. D., \& Prayoga, M. Y. S. (2019).

Pengaruh Kualitas Produk Baju Batik Hem

Terhadap Kepuasan Pelanggan Pada Home Industri Batik Sahara Indah. Jurnal Pemasaran Kompetitif, 2(2), 77-83.

Pasaribu, V. L. D. PENGARUH STORE ATMOSPHERE TERHADAP KEPUTUSAN PEMBELIAN PADA RESTORAN DE'COST GIANT PAMULANG SQUARE TANGERANG SELATAN. Manajerial: Jurnal Manajemen dan Sistem Informasi, 19(2), 156-167.

Pasaribu, V. L. D. P. D. (2018). PENGARUH BIAYA PROMOSI TERHADAP PENINGKATAN PENJUALAN KARTU FLEXI PT. TELEKOMUNIKASI SELULER (TELKOMSEL) JAKARTA (Studi kasus Produk Kartu Flexi Pt. Telkomsel. Jakarta Selatan). Jurnal Pemasaran Kompetitif, 1(2).

PASARIBU, V. L. D. (2017). ANALISIS PENGARUH PROMOSI, KUALITAS PRODUK DAN DESAIN KEMASAN TERHADAP PERSEPSI MEREK YANG BERDAMPAK KEPADA KEPUTUSAN PEMBELIAN HAND AND BODY LOTION MEREK VASELINE (Studi Kasus TIP TOP Ciputat, Tangerang Selatan). Inovasi, 4(2).

Pasaribu, V. L. D., Septiani, F., Rahayu, S., Lismiatun, L., Arief, M., Juanda, A., ... \& Rahim, R. (2021). Forecast Analysis of Gross Regional Domestic Product based on the Linear Regression Algorithm Technique.

Qurbani, D., \& Pasaribu, V. L. D. (2019).

Pengaruh Brand Image Dan Brand Trust

Terhadap Brand Loyalty Nasabah Prudential Syariah Pada PT. Futuristik Artha Gemilang (Studi kasus di kantor cabang agensi Prudential Syariah PT. Futuristik Artha Gemilang Jakarta Selatan). Jurnal Pemasaran Kompetitif, 2(3), 121-135.

Sugiyono.2014. Metode Penelitian Kuantitatif, Kualitatif dan $R \& D$. Bandung, Afabeta. 
Sujarweni, Wiratna. V. 2015. Metodologi Penelitian Bisnis dan Ekonomi. Yogyakarta. Pustaka Baru Press.

Tjiptono, Fandy.2011. "Pemasaran Jasa”, Malang :Bayumedia.

2012.

"Pemasaran

Strategik”Edisi II. Yogyakarta : Andi.

2014. "Pemasaran Jasa-

Prinsip, Penerapan, dan Penelitian" Edisi I. Yogyakarta : Andi.

Tjiptono, Fandy. 2011. Service Quality, and Customer Satisfaction. Edisi Tiga. Yogyakarta.

2015. Strategi Pemasaran.

Yogyakarta : Andi Yogyakarta.

Yamit, Zulian. 2016. “Manajemen Kualitas

Produk dan Jasa”, Edisi pertama Cetakan keenam.Yogyakarta : Kampus UII.

Siswanto, Sabit \& Daniel Widjaja. 2017. Pengaruh Kualitas Layanan Terhadap Kepuasan Konsumen Di PT. Daya Daihatsu Puri Kembangan. Jurnal Ilmah Manajemen Bisnis Vol. 12 No.2.

Sholeha, Ludviyatus, Djaja, Sutrisno, \& Joko Widodo. 2018. Pengaruh Kualitas Pelayanan terhadap Kepuasan PT. AHASS Sumber Jaya Maha Sakti Kecamatan Rogojampi Kabupaten Banyuwangi. Jurnal Ilmiah Ilmu Pendidikan Ekonomi, dan Ilmu Sosial ISSN 1907-9990 Volume 12 No.1.

Panjaitan, Januar Efendi \& Yuliati, Ai Lili. 2016. Pengaruh Kualitas Pelayanan Terhadap Kepuasan Pelanggan Pada JNE Cabang Bandung. DeReMa Jurnal Manajemen Vol.11 No.2

Nilasari, Eswika \& Istiatin. 2015. Pengaruh Kualitas Pelayanan Terhadap Kepuasan Konsumen Pada Dealer PT. Ramayana Motor Sukoharjo. Jurnal Paradigma ISSN : 1693-0827 Vol.13, No.1 